\title{
14-3-3ろ loss leads to neonatal lethality by microRNA-126 downregulation-mediated developmental defects in lung vasculature
}

\author{
Jun Yang ${ }^{1,3+}$, Sonali Joshi ${ }^{1 \dagger}$, Qingfei Wang ${ }^{1}$, Ping Li ${ }^{1}$, Hai Wang ${ }^{1}$, Yan Xiong ${ }^{1}$, Yi Xiao ${ }^{1}$, Jinyang Wang ${ }^{1}$, \\ Jan Parker-Thornburg ${ }^{2}$, Richard R. Behringer ${ }^{2,3}$ and Dihua $\mathrm{Yu}^{1,3,4^{*}}$
}

\begin{abstract}
Background: The 14-3-3 family of proteins have been reported to play an important role in development in various mouse models, but the context specific developmental functions of 14-3-3 $\zeta$ remain to be determined. In this study, we identified a context specific developmental function of 14-3-3

Results: Targeted deletion of $14-3-3 \zeta$ in the $(57 \mathrm{BI} / 6 \mathrm{~J}$ murine genetic background led to neonatal lethality due to respiratory distress and could be rescued by out-breeding to the CD-1 or backcrossing to the FVB/NJ congenic background. Histological analysis of lung sections from 18.5 days post coitum embryos (dpc) showed that 14-3$3 \zeta-1-$ lung development is arrested at the pseudoglandular stage and exhibits vascular defects. The expression of miR-126, an endothelial-specific miRNA known to regulate lung vascular integrity was down-regulated in the lungs of the 14-3-3 $3-/-$ embryos in the C57BI/6J background as compared to their wild-type counterparts. Loss of 14-3-3 3 in endothelial cells inhibited the angiogenic capability of the endothelial cells as determined by both trans-well migration assays and tube formation assays and these defects could be rescued by re-expressing miR-126. Mechanistically, loss of 14-3-3Z led to reduced Erk1/2 phosphorylation resulting in attenuated binding of the transcription factor Ets2 on the miR-126 promoter which ultimately reduced expression of miR-126.
\end{abstract}

Conclusion: Our data demonstrates that miR-126 is an important angiogenesis regulator that functions downstream of 14-3-3 3 and downregulation of miR-126 plays a critical role in 14-3-3Z-loss induced defects in lung vasculature in the $\mathrm{C} 57 \mathrm{BI} / 6 \mathrm{~J}$ genetic background.

Keywords: 14-3-3ろ, miR-126, Lung development, Angiogenesis

\section{Background}

The mammalian 14-3-3 protein family consists of seven isoforms $(\beta, \tau, \varepsilon, \zeta, \eta, \gamma$ and $\sigma)$. They modulate multiple signaling pathways in diverse biological processes by binding to specific phospho-specific motifs on target proteins and thereby regulate their function, activity, stability, or localization $[1,2]$. Due to their ability to interact with a plethora of target proteins, they are

\footnotetext{
${ }^{*}$ Correspondence: dyu@mdanderson.org

†Jun Yang and Sonali Joshi contributed equally to this work

1 Department of Molecular and Cellular Oncology, Unit 108, The

University of Texas MD Anderson Cancer Center, 1515 Holcombe

Boulevard, Houston, TX 77030, USA

Full list of author information is available at the end of the article
}

reported to play an important role in the regulation of cell cycle, DNA damage repair, cell proliferation, cell polarity, programmed cell death and cell metabolism, etc. [3-8]. In spite of exhibiting a high degree of homology, knockout mouse models of different 14-3-3 family members have revealed distinctive biological functions for the different isoforms $[1,9,10]$, indicating that the various isoforms can exert unique functions which cannot be compensated by other members of the 14-3-3 family.

14-3-3 $\zeta$ has been implicated in various human diseases such as Alzheimer's disease [11, 12], progressive multifocal leukoencephalopathy [13], Huntington disease [14], Creutzfeldt-Jakob disease [15] and is reported to be 
upregulated in multiple cancer types, including lung [16, $17]$, breast $[2,18,19]$, ovarian [20], head and neck [21] as well as lymphomas [22].

Previous studies on the developmental role of $14-3-3 \zeta$ have identified that $14-3-3 \zeta$ functions in neuronal development and in regulation of adipogenesis [23]. On a SV129 background, $14-3-3 \zeta-/-$ mice were reported to exhibit behavioral and cognitive defects similar to those observed in schizophrenia, autism spectrum disorder and bipolar disorder [24]. Additionally, these mice were found to manifest enhanced locomotor hyperactivity due to dysregulation of dopamine signaling [25]. On a Balb/c

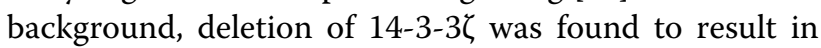
hippocampal defects with a decrease in spatial memory but they did not exhibit enhanced locomotor activity as

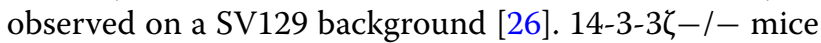
have also been reported to exhibit reduced deposition of visceral fat as loss of 14-3-3 $\zeta$ promotes autophagy mediated degradation of $\mathrm{CEBP} / \delta$ preventing induction of the master adipogenesis regulators PPAR $\gamma$ and C/EBP $\alpha$ [23]. However, these previous studies did not reveal a role of 14-3-3 $\zeta$ in lung development.

In this study, we generated a 14-3-3 $\zeta$ hypomorphic mutant mouse (14-3-3 $\zeta-/-)$ model for studying the 14-3-3 $\zeta$ gene function in vivo. We found that targeted deletion of $14-3-3 \zeta$ on a C57Bl/6J genetic background led to neonatal lethality due to respiratory distress, which resulted from miR-126 downregulation-induced defects in lung vasculature. Our findings demonstrate a unique and essential role of 14-3-3 $\zeta$ in normal development in a genetic background specific manner.

\section{Methods}

Generation and maintenance of 14-3-3 3 knockout mouse

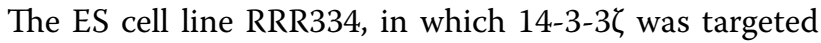
according to the $5^{\prime}$ RACE data from the Baygenomics database, was obtained from Mutant Mouse Regional Resource Center (MMRRC). RT-PCR was performed to confirm that the cell line inactivates 14-3-3 . The primer sequence for the exogenous was forward: $5^{\prime}$-TGCTGAGAAAAAGCAGCAGA and reverse: 5'-GACAGTATCGGCCTCAGGAAGATCG. The primer sequence for endogenous 14-3-3 $\zeta$ control PCR was forward: 5'-TGCTGAGAAAAAGCAGCAGA and reverse: 5'-TTGTCATCACCAGCAGCAAC. The genetic engineered mouse facility at MD Anderson Cancer Center injected the cells into $\mathrm{B} 6(\mathrm{Cg})-\mathrm{Tyr}^{\mathrm{c}}-{ }^{2 \mathrm{j}} / \mathrm{J}$ (The Jackson Laboratory, Bar Harbour, ME, Stock \#000058) blastocysts. Chimeras were mated with $\mathrm{B} 6(\mathrm{Cg})-\mathrm{Tyr}^{\mathrm{c}}-2 \mathrm{j} / \mathrm{J}$ mice to test germline transmission and obtain 14-3-3 $\zeta$ knockout founder mice. The primer sequences for PCR genotyping were forward: 5'-CAACCATGTTGGGATAGAGG homologous to $14-3-3 \zeta$ intron 3, reverse:
5'-CCAAATAAGCCTTCCCTTCC homologous to intron 3 and 5'-AAGGGTCTTTGAGCACCAGA homologous to the gene trap vector. PCR resulted in 954bp fragment from the wild-type allele and a 544-bp fragment from the mutant allele. Mice were backcrossed into $\mathrm{C} 57 \mathrm{Bl} / 6 \mathrm{~J}$ and $\mathrm{FVB} / \mathrm{NJ}$ congenic background as determined by genome scan using a panel of simple sequence length polymorphism (SSLP) (microsatellite) markers, or outbred to $\mathrm{CD}-1$ genetic background respectively and maintained thereafter. The C57Bl/6J and FVB/NJ mouse breeders were purchased from the Jackson Laboratory (Bar Harbor, ME). The CD-1 breeders were purchased from Charles Rivers (Wilmington, MA). All animal work was performed under an IACUC-approved protocol. University of Texas MD Anderson Cancer Center is an AAALAC accredited institution.

\section{Cell culture}

The mouse endothelial cell line ARBEC was obtained from Dr. Fidler's lab at MDACC. The endothelial cells were generated from $\mathrm{H}-2 \mathrm{~Kb}$-tsA58 mice immortalized with SV40 large $T$ antigen. The ARBEC cells were cultured using DMEM supplemented with 10\% FBS. The transfection was performed using Lipofectamine 2000 using standard protocol.

MCF7 cells were cultured using DMEM supplemented with $10 \%$ FBS. N-terminal 139aa of $14-3-3 \zeta$ was cloned into pcDNA3 and later transfected into MCF7 cell lines. Stable clones $(\Delta \mathrm{C} 1$ and $\Delta \mathrm{C} 12)$ were selected with $\mathrm{G} 418$ and high expressers were examined by western blot and maintained since. Mouse embryonic fibroblast (MEF) cells were obtained from E13.5 B6 embryos. The embryos were minced, cut and filtered. Cells were then centrifuged, resuspended in DMEM supplemented with $10 \%$ FBS and plated. Control pre-microRNA and pre-miR126 were ordered from Exiqon.

\section{Tissue collection and histological analysis}

The mouse embryos were collected by C-section at 18.5 dpc (days post coitum). The lung tissues were collected after euthanasia following an IACUC-approved protocol. Tissues were fixed in $10 \%$ neutral buffered formalin for $12-18 \mathrm{~h}$. The samples were stored in $70 \%$ ethanol and then embedded in paraffin. Paraffin sections $(5 \mu \mathrm{m})$ were stained with hematoxylin and eosin. Histological analysis were independently evaluated by at least two pathologists (Y.X., W.H. and Q.Z.). Immunohistochemistry (IHC) was performed as previously described [19]. Antibodies used were Ki67 (DAKO, Carpentaria, CA M7249), CD34 (eBioscience, San Diego, CA 14-0341), 14-3-3 (C-16, Santa Cruz, Santa Cruz, CA sc-1019), SP-A (Santa Cruz sc-13977), and AQP5 (Calbiochem, Germany 178615). For IHC analysis and quantification, 
10 fields were randomly chosen at $200 \times$ magnification. The total number of cells and positive cells were counted, and the average percentage of positive cells was determined.

\section{Immunoblotting}

Tissues were collected from the mice. Protein extracts were prepared by homogenizing samples in tissue lysis PBSTDS buffer $[10 \mathrm{mmol} / \mathrm{L}$ sodium phosphate $(\mathrm{pH}$ 7.3), $154 \mathrm{mmol} / \mathrm{L} \mathrm{NaCl}, 5 \%$ sodium deoxycholate, $1 \%$ SDS] using a tissue grinder, followed by centrifugation to remove particulate matter and lipids. Immunoblotting was performed as previously described by $\mathrm{Lu}$ et al. [19]. Antibodies used were anti-HA high affinity (clone 3F10, Roche 11867423001), 14-3-3 (C-16, Santa Cruz sc-1019), Erk (Cell Signaling 4695), phosphor-Erk (T202/ Y204, Cell Signaling 4370), Mek1 (Cell Signaling 9126), phosphor-Mek1 (S221, Cell Signaling 2338), Ets1 (c-20, Santa Cruz sc-350), Ets2 (c-20, Santa Crux sc-351), Akt (Cell Signaling 9272), phosphor-Akt (S473, Cell Signaling 3787), $\beta$-actin (Sigma A5441), and tubulin (Sigma T5168). The antibodies were mainly used at a 1:1000 dilution.

\section{Quantitative RT-PCR for microRNA quantification}

RNA of the tissue samples was extracted using Trizol (Invitrogen, Carlsbad, CA) following the manufacturer's instructions. The specific primers and probe for miR126 real-time PCR were purchased from Applied Biosystems. Reverse transcription was performed using the Taqman MicroRNA Reverse Transcription kit (Applied Biosystems 4366569), and real-time PCR was performed using the Taqman Universal PCR Master Kit (Applied Biosystems 4324018) and iQ SyBR Green Supermix (Bio-Rad 170-8882). The primer sequences for PECAM1 were forward: 5'-CTGGTGCTCTATGCAAGCCT and reverse: $5^{\prime}$-AGTTGCTGCCCATTCATCAC. The primer sequences for $18 \mathrm{~S}$ ribosomal RNA were forward: 5'-AACCCGTTGAACCCCATT and reverse: 5'-CCATCCAATCGGTAGTAGCG. Control pre-microRNA and pre-miR126 were ordered from Exiqon.

\section{Transwell migration assay}

Mouse endothelial cells $\left(3 \times 10^{4}\right)$ resuspended in $500 \mu \mathrm{L}$ of serum-free medium were seeded in the top chamber of 24-well 8- $\mu \mathrm{m}$ pore transwell plates. $600 \mu \mathrm{L}$ of medium containing $10 \%$ FBS was used as chemo-attractant in the bottom chamber. The plates were incubated at $37^{\circ} \mathrm{C}$ for $4 \mathrm{~h}$. The cells were fixed in 10\% neutral buffered formalin for $1 \mathrm{~h}$ before staining with $0.5 \%$ crystal violet for $1 \mathrm{~h}$. The plates were then flushed under tap water to remove excessive dye. The cells that did not migrate through the wells were wiped away by cotton tips. Images were taken with a Zeiss Discovery V20 microscope with the supplied software Axiom. The entire wells were quantified and three replicates were performed for statistical analysis.

Quantification of the migrated cells was performed using Adobe Photoshop and ImageJ software.

\section{Tube formation assay}

Matrigel (BD, Franklin Lakes, NJ 356231) was thawed at $4{ }^{\circ} \mathrm{C}$ overnight before assay, and then $500 \mu \mathrm{L}$ of Matrigel was added into each well of the 24-well plate. The plates were incubated at $37^{\circ} \mathrm{C}$ for $30 \mathrm{~min}$ to $1 \mathrm{~h}$ to form gel. Cells $\left(3 \times 10^{5}\right)$ resuspended in DMEM/F-12 medium containing 10\% FBS were plated above the Matrigel and incubated for $6 \mathrm{~h}$ at $37^{\circ} \mathrm{C}$. The formation of the tube structure by the endothelial cells was imaged with an Olympus inverted fluorescence microscope and quantified using the ImageJ software. Three replicates were performed and five images were taken from each well for analysis.

\section{Statistical analyses}

Statistical differences were assessed with two-tailed Student's $t$ test or one-way ANOVA. A $p$ value of $<0.05$ was considered statistically significant.

\section{ChIP assay}

Chromatin proteins were cross linked to chromatin with formaldehyde and sheared into 400-1000 bp fragments. Nucleoprotein complexes were immunoprecipitated using antibody to Ets-1, Ets-2, or control IgG antibody. The precipitated DNA fractions were analyzed by Quantitative-PCR for the presence of the miR-126 proximal regulatory region encompassing the EBS1 and EBS2 (region -150 to $+100 \mathrm{bp}$ ). Input DNA was used as a positive control.

\section{Results}

\section{Generation of 14-3-3 3 knockout mice}

A gene trap approach was used to generate 14-3-3 knockout mice. RRR334 ES cells were obtained from the Mutant Mouse Regional Resource Center (MMRRC) and the disruption of 14-3-3 $\zeta$ at exon 3 was confirmed by RTPCR (Additional file 1: Figure S1A). The integration site of the gene trap vector was found to be located $3351 \mathrm{bp}$ downstream of exon 3 in the 14-3-3 gene by PCR amplification followed by DNA sequencing (Additional file 1: Figure S1B). The site of genomic integration was further confirmed by southern blotting (data not shown). Based on the integration site, a forward primer homologous to intron 3 and a reverse primer homologous to the gene trap vector were used for genotyping (Fig. 1a, b). The ES cells were injected into C57Bl/6J albino mouse blastocysts and chimera mice with high ES cell contribution 


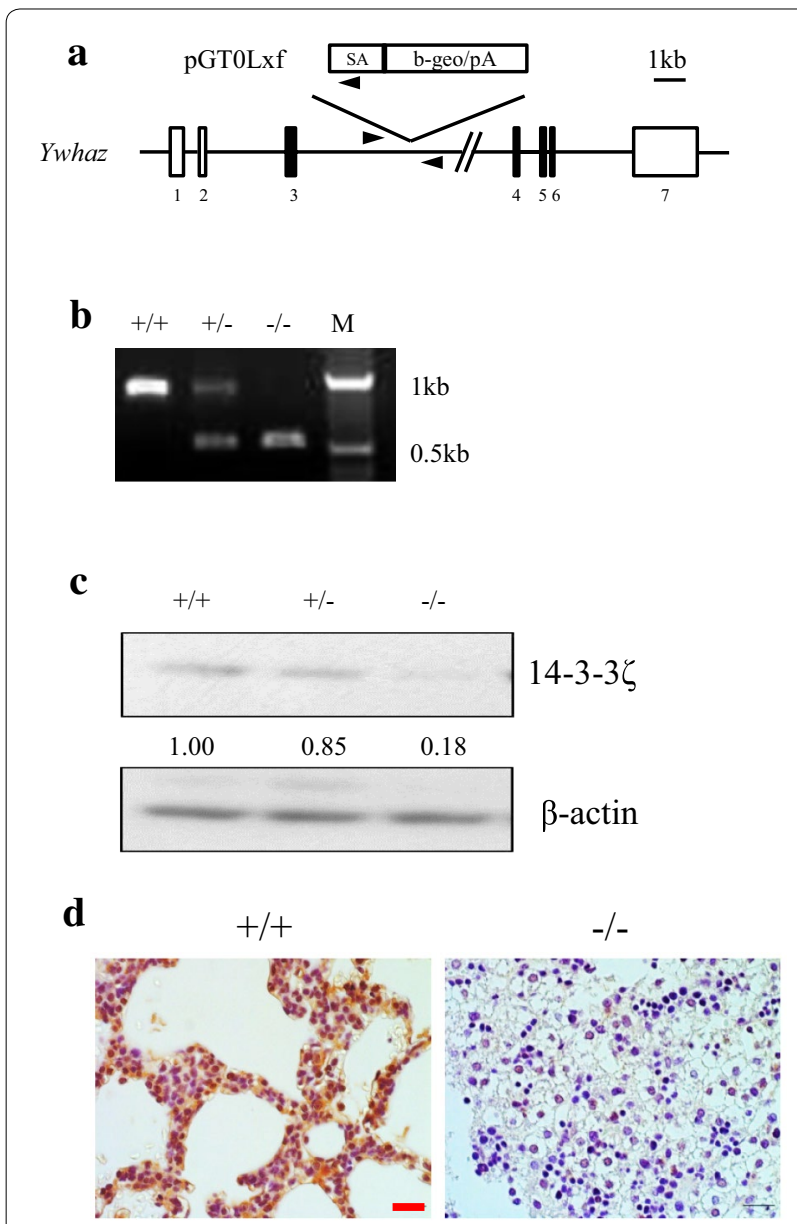

Fig. 1 Generation and characterization of 14-3-3 knockout mice. a Schematic map showing that the gene trap vector integrated into intron 3 of the 14-3-3 gene (Ywhaz). Ywhaz is the HUGO Gene Nomenclature Committee-approved gene symbol for 14-3-3Z. The lines represent the introns for the $14-3-3 \zeta$ gene and the rectangles signify the exons. The solid sections indicate the coding region for 14-3-3 protein. The gene trap vector pGTOLxf was integrated $\sim 3.3 \mathrm{~kb}$ downstream of exon 3. SA indicates the splice acceptor sequence of mouse En2 exon 2. $\beta$-Geo/pA indicates the fusion of $\beta$-galactosidase and neomycin transferase followed by SV40 polyadenylation signal. The arrows indicate the primers for genotyping. The scale bar represents $1 \mathrm{~kb}$ length of DNA sequence. b PCR genotyping for 14-3-3Z knockout mice: $+/+,+/-$, and $-/-$ indicate $14-3-3 \zeta$ wild-type, heterozygous, and homozygous mutant alleles, respectively. M indicates marker. Wild-type allele generated a 954-bp band, and the mutant allele generated a 544-bp PCR product. c Western blot confirming the loss of 14-3-3 expression in mouse embryonic fibroblast (MEF) cells. $\beta$-Actin served as loading control. Quantification of relative 14-3-3ろ expression level was shown below the western panel. $\mathbf{d}$ Immunohistochemical (IHC) staining of 14-3-3 3 expression in the neonatal lung tissue dissected from $+/+$ and $-/-$ mice. Scale bar indicates $50 \mu \mathrm{m}$ in length

based on their fur color were mated with $\mathrm{C} 57 \mathrm{Bl} / 6 \mathrm{~J}$ albino mice to obtain 14-3-3 $\zeta$ heterozygous $(+/-)$ founder mice. The founder male and female $14-3-3 \zeta+/-$ mice were mated to generate $14-3-3 \zeta$ homozygous mutant $(-/-)$ mice. $14-3-3 \zeta$ protein expression was significantly reduced or lost in MEF cells as well as multiple tissue types from the knockout mouse (Fig. 1c, d and Additional file 1: Figure S2C).

Based on the integration site of the gene trap vector, the knockout mouse should express a truncated 14-3-35 protein containing 139 amino acids of the $\mathrm{N}$-terminal part of $14-3-3 \zeta$ protein fused to the $\beta$-geo cassette. To test whether the $\mathrm{N}$-terminal part of $14-3-3 \zeta$ protein is functional, a vector containing the HA-tagged N-terminal fragment of 14-3-3 $\zeta$ with deletion of the C-terminal target protein binding groove $(\Delta \mathrm{C} 14-3-3 \zeta)[27,28]$ was transfected into MCF7 breast cancer cells. The expression of the HA-tagged $\Delta C 14-3-3 \zeta$ was detectable only in the presence of the proteosomal inhibitor MG132 (Additional file 1: Figure S2A) and it did not enhance cell proliferation or induce activation of the Ras/Raf/Erk and PI3K/Akt pathways (Additional file 1: Figure S2B, C) as would be expected with full length 14-3-3 [29]. Thus the $\mathrm{N}$-terminal fragment of $14-3-3 \zeta$ is non-functional and the $14-3-3 \zeta-1-$ mouse generated by the gene-trap approach is a strong hypomorphic model for studying the function of $14-3-3 \zeta$ in vivo.

\section{4-3-3 - -/- mice are neonatal lethal with defective lung development}

After mating heterozygous male and female founders, approximately $5 \%$ of the litter was homozygous for the $14-3-3 \zeta$ gene trap allele, as determined by genotyping 10 days after birth (Table 1). Failure to yield the expected $25 \%$ homozygous births suggested that $14-3-3 \zeta$-loss may be lethal either during embryogenesis or soon after birth [30, 31]. Genetic background can be an important determinant of phenotypes observed in knockout mice [32, 33]. We backcrossed the gene trap allele on to a congenic C57Bl/6J genetic background. 14-3-3 3 expression level was remarkably downregulated in this genetic background (Fig. 1c, d). Remarkably, genotyping revealed no surviving homozygous mutant pups (Table 1), confirming the lethal phenotype observed on the B6/129P2 F2 hybrid genetic background strain. To test whether out-crossing

Table 1 Genotype of pups generated by mating heterozygous breeders under different genetic background

\begin{tabular}{lllcr}
\hline Strainlgeno & $+/+$ & $\mathbf{1}$ & $\boldsymbol{- l}$ & p value \\
\hline B6/129P2 F2 & 22 & 39 & 3 & 0.0052 \\
B6 congenic & 58 & 72 & 0 & $<0.0001$ \\
B6-E18.5 & 16 & 32 & 15 & 0.9879 \\
CD-1 & 36 & 73 & 38 & 0.9849 \\
FVB/NJ & 27 & 53 & 25 & 0.9809 \\
\hline
\end{tabular}


to different genetic backgrounds could circumvent the lethal phenotype, 14-3-3 $\zeta$ heterozygous mice were bred on the CD-1 outbred strain. Heterozygous crosses resulted in $\sim 25 \%$ homozygous mutant viable pups (Table 1 and Additional file 1: Figure S3A). Backcrossing the $\mathrm{C} 57 \mathrm{Bl} / 6 \mathrm{~J}$ congenic $14-3-3 \zeta$ heterozygous mice to the $\mathrm{FVB} / \mathrm{NJ}$ congenic background also resulted in viable pups at the expected ratios (Table 1 and Additional file 1: Figure S3B). The expression of other 14-3-3 isoforms was unaltered by loss of 14-3-3 $\zeta$ (Additional file 1: Figure $\mathrm{S} 3 \mathrm{C}$ ). Thus, outbreeding to $\mathrm{CD}-1$ and $\mathrm{FVB} / \mathrm{NJ}$ background rescued the neonatal lethality observed on the C57Bl/6J strain.

To determine the developmental stage when the 14-3$3 \zeta-1-$ mice on the C57Bl/6J background die, we dissected embryos from heterozygous crosses at 18.5 days post coitum (dpc). The ratio of the knockout embryos matched the predicted Mendelian ratios (Table 1). However, the 14-3-3 - - - embryos exhibited a pale color and died minutes after birth indicating respiratory failure (Fig. 2a). The lungs of the wild-type $(+/+)$ mice floated on water, whereas the lungs of the 14-3-3 $-1-$ embryos and newborn pups sank in water (Fig. 2b), indicating a failure to inflate. These results demonstrated that neonatal lethality of the $14-3-3 \zeta-/-$ mice is due to respiratory failure.

Hematoxylin and eosin (H\&E) staining of the lung sections of the $18.5 \mathrm{dpc}$ embryos showed that the lungs of the $14-3-3 \zeta-/-$ mice lacked saccular structures and exhibited increased mesenchymal compartments and thickened saccular septae (Fig. 2c). Amid that 14-3$3 \zeta$ expression level was significantly downregulated (Fig. 1d), no significant difference in pneumocyte proliferation was detected by Ki-67 immunohistochemical (IHC) staining (Fig. 2d). Pneumocyte differentiation was not altered by loss of 14-3-3 $\zeta$ as evident by IHC staining of type II pneumocyte marker, pulmonary surfactantassociated protein A (SP-A), and type I pneumocyte marker, aquaporin isoform 5 (AQP5) (Fig. 2e, f). Loss of 14-3-3 $\zeta$ resulted in fragmented blood vessels that were surrounded by leukocyte aggregates and also decreased endothelial cells as analyzed by CD34 staining (Fig. 2g). Thus defects in lung vasculature result in the respiratory

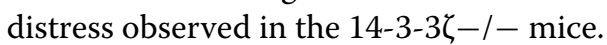

\section{Loss of 14-3-3 3 impedes angiogenesis via downregulation} of miR-126

Analysis of the Mouse Genome Informatics (MGI) database (http://www.informatics.jax.org/) revealed that targeted deletion of the endothelial specific miR-126 was reported to result in a lethal phenotype [34] similar to the $14-3-3 \zeta-/-$ mice on a $\mathrm{C} 57 \mathrm{Bl} / 6 \mathrm{~J}$ genetic background. Quantitative RT-PCR analysis showed that miR-126 expression in the lungs of the 14-3-3 $-1-$ - embryos in the $\mathrm{C} 57 \mathrm{Bl} / 6 \mathrm{~J}$ background was significantly reduced compared to their wild-type counterparts (Fig. 3a). Notably, miR-126 expression in the lungs of wild-type C57Bl/6J mice is significantly lower than that in the lungs of FVB/ $\mathrm{NJ}$ and CD-1 mice of the same age (Fig. 3b), suggesting that further attenuating miR-126 expression in the already lower miR-126 expressing C57Bl/6J lungs may account for the lethality phenotype observed on that background.

To determine the contribution of miR-126 downregu-

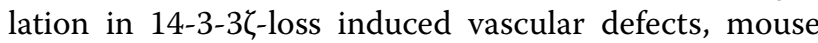
endothelial cells were stably transfected with two distinct shRNAs targeting 14-3-3 $\zeta$ and a scrambled shRNA was used as a control (Fig. 3c). Loss of 14-3-3 3 expression led to a significant downregulation of miR-126 (Fig. 3d) and inhibited the angiogenic functionality of the endothelial cells as determined by both migration and tube formation assays (Fig. 4a, b). Expression of a miR-126 mimetic (pre-miR-126) (Fig. 4c) in 14-3-3 5 knockdown mouse endothelial cells rescued their migration and tube formation capabilities (Fig. 4a, b lower panels). These results demonstrated that downregulation of the angiogenesis regulator miR-126 plays a critical role in $14-3-3 \zeta$-loss induced lung vasculature defects on the $\mathrm{C} 57 \mathrm{Bl} / 6 \mathrm{~J}$ background.

The Raf/Mek/Erk regulated transcription factors Ets1 and Ets2 are important transcriptional regulators of miR-126 [35]. As 14-3-3 $\zeta$ plays an important role in Raf- 1 activation [36, 37], loss of 14-3-3 may result in attenuated activation of the Raf/Mek/Erk pathway leading to decreased Ets1 and Ets2 mediated transcription of miR-126. Indeed, loss of 14-3-3ఢ in mouse endothelial cells reduced Erk phosphorylation (Fig. 5a), and attenuated binding of Ets2 to the miR-126 promoter (Fig. 5b) while Ets1 binding was not significantly altered (Fig. 5c).

(See Figure on next page)

Fig. 2 14-3-3 mediated neonatal lethality and associated defects in lung development. a 18.5 dpc embryos were dissected using caesarean section. Representative photos of $14-3-3 \zeta$ wild type $(+/+)$ and homozygous mutant (-/-) are shown as indicated. $\mathbf{b}$ Lung tissues from the embryos were immersed in water to determine buoyancy. $\mathbf{c}$ Hematoxylin and eosin staining of the lungs dissected from the embryos. Sample size is indicated. $\mathbf{d} \mathrm{HC}$ staining for Ki-67 on the lungs dissected from +/+ and -/ - embryos. e $\mathrm{HC}$ staining for SP-A on the lungs dissected from $+/+$ and $-/-$ embryos. $\mathbf{f} \| \mathrm{HC}$ staining for AQP5 on the lungs dissected from $+/+$ and $-/-$ embryos. $\mathbf{g} \| \mathrm{HC}$ staining for CD34 on the lungs dissected from $+/+$ and $-/-$ embryos. Length of the scale bar represents $50 \mu \mathrm{m}$ in each panel. $\mathbf{d}-\mathbf{g}$ Right: the quantification of the IHC stainings by immunoreactive score (IRS). ${ }^{* * *},{ }^{* *},{ }^{*}$ Indicate $p<0.001,0.01$, and 0.05 , respectively. n.s.: not significant 


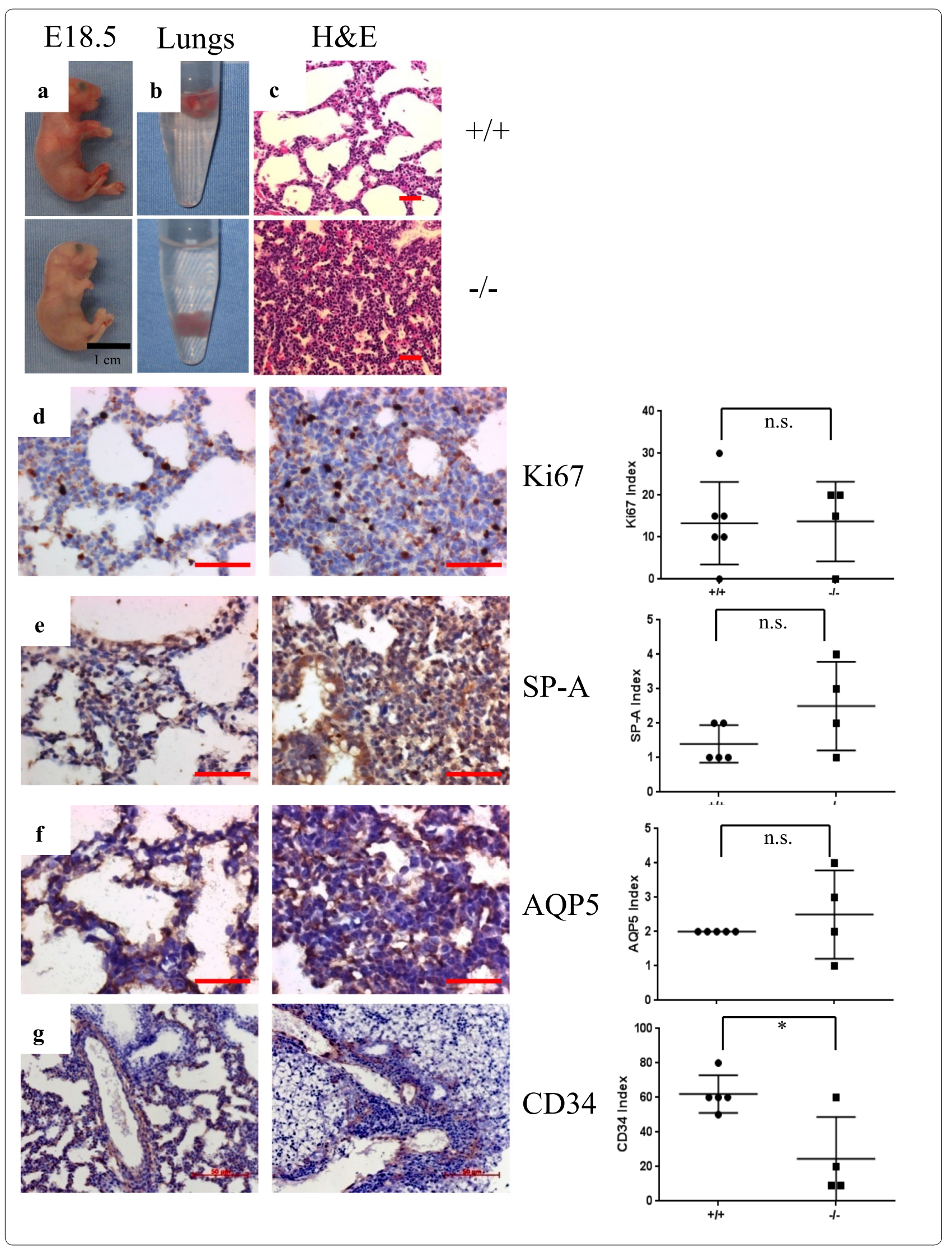




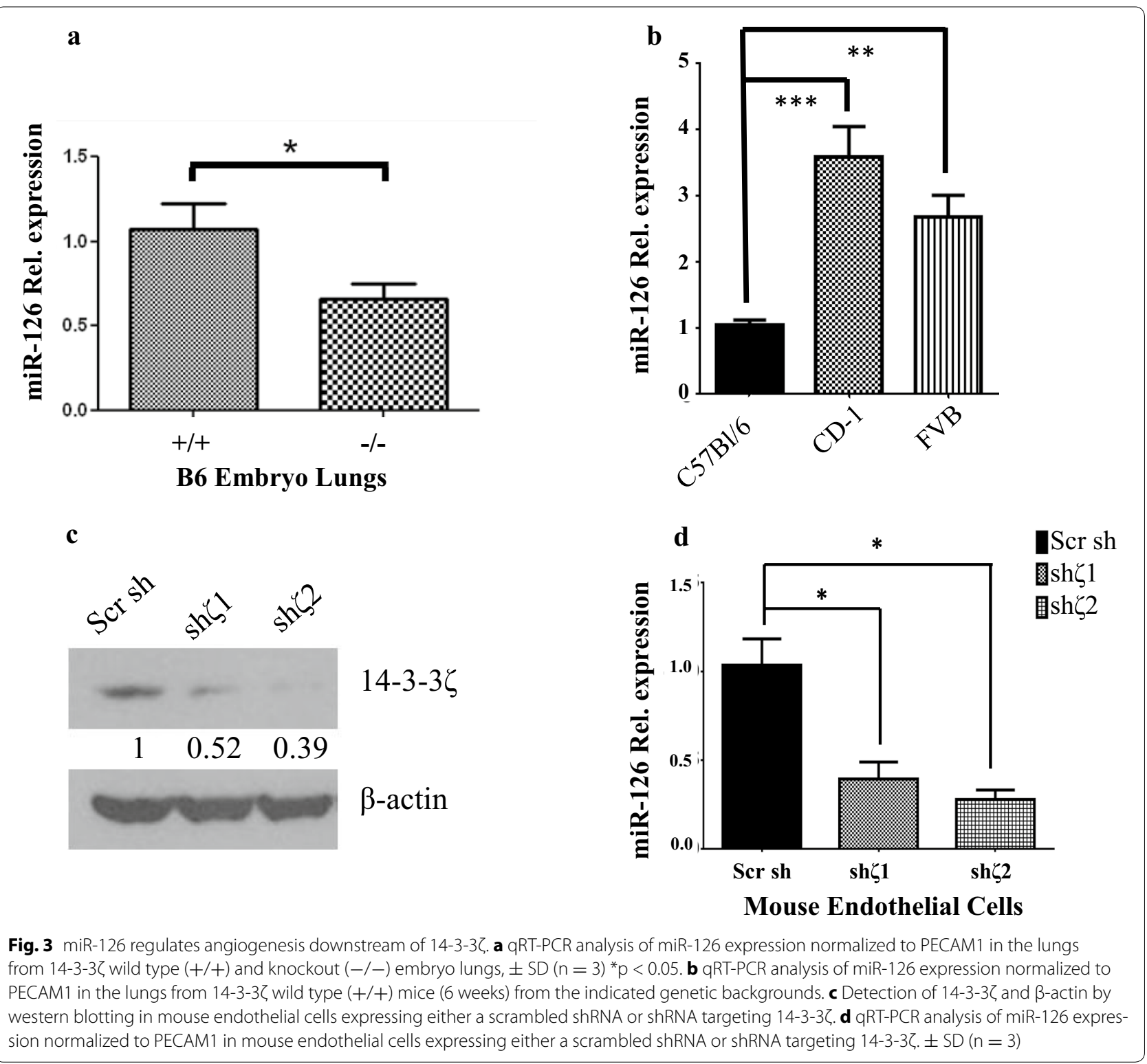

Inhibition of Erk activity in mouse endothelial cells using a MEK1/2 inhibitor (AZD6244) also attenuated miR-126 expression (Fig. 5d, e) and reduced Ets2 binding to the miR-126 promoter (Fig. 5f) while Ets1 binding was unaffected (Fig. 5g). These results suggest that loss of 14-3-3 attenuates miR-126 transcription by decreased binding of Ets2 to the miR-126 promoter.

\section{Discussion}

14-3-3 isoforms exhibit unique non-overlapping biological functions. 14-3-3 $\sigma$ stabilizes p53, thus suppresses tumor growth [38-40] and is frequently lost in cancer [41-43]. 14-3-3 $\sigma$ mediates keratinocyte proliferation and differentiation in vivo [44]. $14-3-3 \varepsilon$ can enhance TGF- $\beta$ signaling [45], bind to poly A polymerase and regulate its cellular localization [46]. Targeted disruption of $14-3-3 \varepsilon$ in mice results in embryonic lethality from hippocampal and cortical defects while 14-3-3e heterozygous mice exhibited neuro-developmental defects that mimic the Miller-Dieker syndrome [47]. 14-3-3 $\gamma$ knockout mice do not display a discernible phenotype [48] but it can affect PDGF signaling in smooth muscle cells [49]. 14-33т regulates E2F stability, is required for autophagy [50] and targeted deletion of 14-3-3 $\tau$ in mice leads to embryonic lethality from gross developmental defects [51]. We uncovered an unexpected role for 14-3-3 $\zeta$ in mediating vascular integrity during lung development. Thus loss of $14-3-3 \zeta$ in mice leads to distinct physiological defects and 


\section{a}

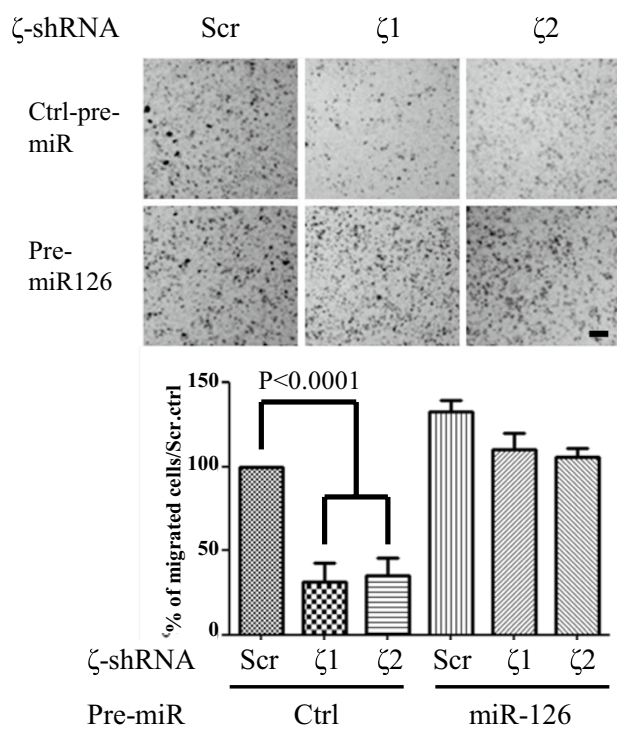

b

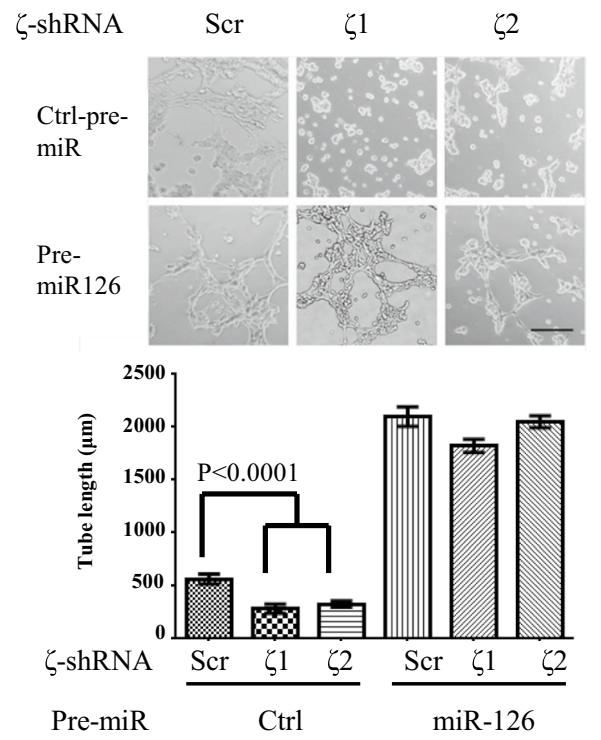

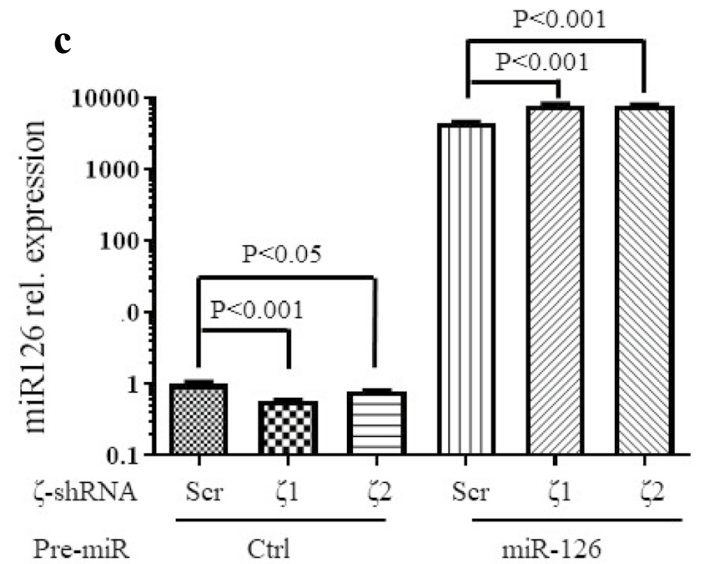

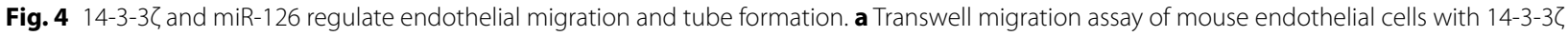
knockdown and rescue by overexpression of exogenous miR-126. Cells stably expressing scramble or 14-3-3Z shRNA were transfected with control or pre-miR-126. Representative result is shown in the top panel and the bottom panel shows the quantification. Scale bar indicates $50 \mu m$ in length. b Tube formation assay with exogenously expressed miR-126 in the 14-3-3 knockdown mouse endothelial cells. Representative results are shown in the top panel and the bottom panel shows the quantification. Scale bar indicates $50 \mu \mathrm{m}$ in length. c Mouse endothelial cells stably transfected with either scrambled shRNA or shRNA targeting 14-3-3ろ were transfected with pre-miR-126. MiR-126 expression was analyzed by qRT-PCR and normalized to PECAM1, $\pm S D(n=3)$. Three independent transwell experiments were performed and three random fields from the tube formation assay were analyzed for statistical analysis

pathological effects in various genetic backgrounds that cannot be compensated by other 14-3-3 isoforms in vivo. Together, these studies indicated that specific 14-3-3 isoforms, including 14-3-3 , have distinctive biological functions in normal development and in diseases.

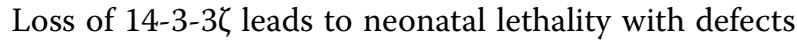
in lung development on the $\mathrm{C} 57 \mathrm{Bl} / 6 \mathrm{~J}$ genetic background, indicating that $14-3-3 \zeta$ plays an indispensable role in normal development. Mechanistic insights came from our finding that loss of $14-3-3 \zeta$ on the $\mathrm{C} 57 \mathrm{Bl} / 6 \mathrm{~J}$ background phenocopies miR-126 knockout mice. MiR126 is an endothelial cell-specific microRNA, and miR126 loss resulted in neonatal lethality and lung deflation due to vascular disintegration and inhibition of angiogenesis [34]. Additionally, zebrafish studies have suggested a role of miR-126 in facilitating the lung vasculature 

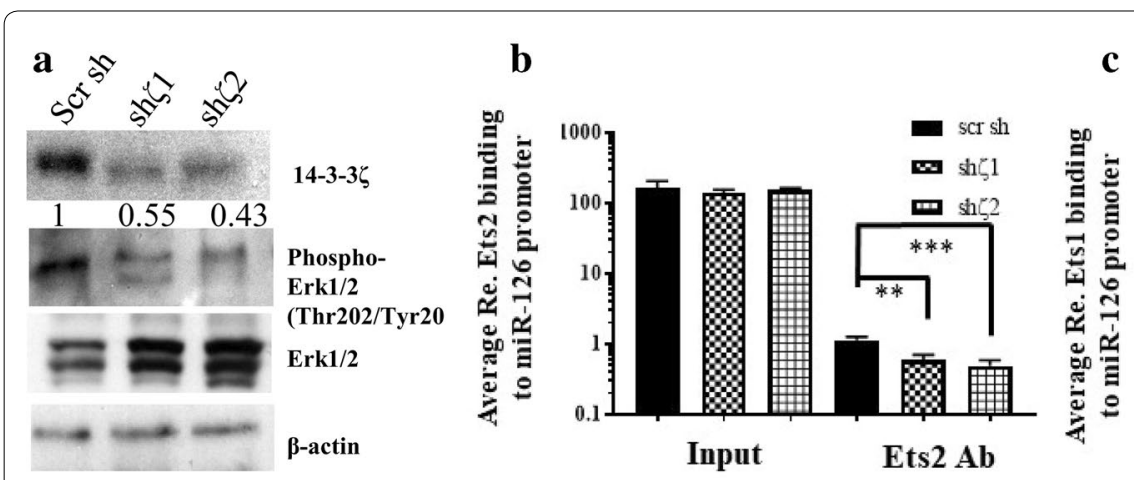

c

d

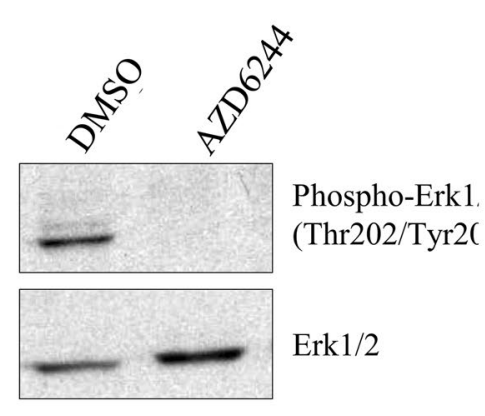

e
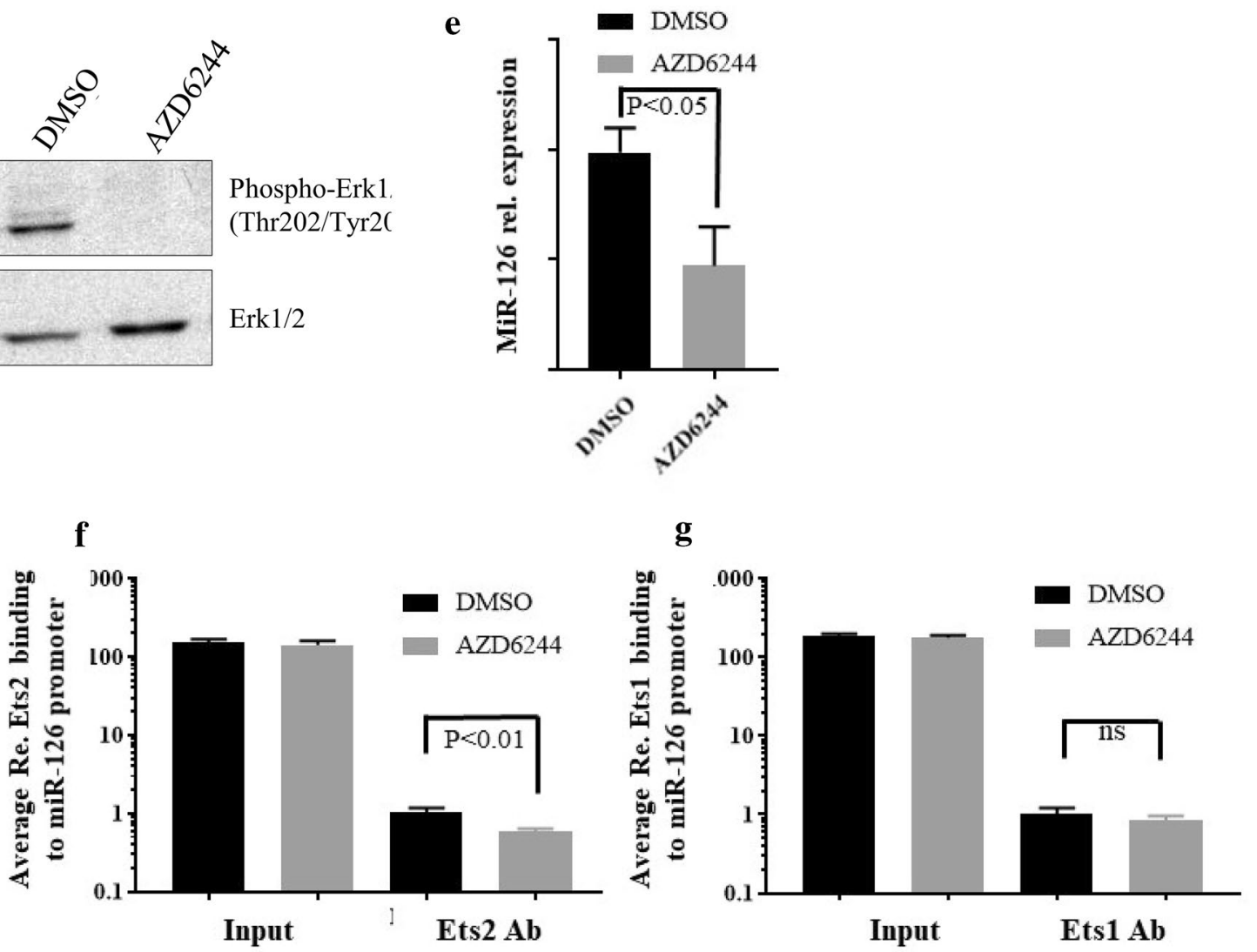

Fig. 5 14-3-3ろ mediates miR-126 transcription by modulating Ets2 activity. a Detection of 14-3-3ろ, phosphor-Erk 1/2 (Thr202/Tyr204), total Erk1/2 and $\beta$-actin by western blotting in mouse endothelial cells expressing either a scrambled shRNA or shRNA targeting 14-3-3Z. b, c ChIP analysis of Ets2 and Ets 1 binding to the miR-126 promoter in mouse endothelial cells expressing either a scrambled shRNA or shRNA targeting 14-3-3ろ, \pm SD $(n=3)$. d Analysis of phosho-Erk (Thr202/Tyr204) and Erk1/2 in mouse endothelial cells treated with either DMSO or the ERK1/2 inhibitor AZD6244 by western blotting. e qRT-PCR analysis of miR-126 expression relative to PECAM1 in mouse endothelial cells treated with either DMSO or AZD6244, $\pm \mathrm{SD}(\mathrm{n}=3)$. $\mathbf{f}$ ChIP analysis of Ets2 binding to the miR-126 promoter in mouse endothelial cells treated with either DMSO or AZD6244. \pm SD. g ChIP analysis of Ets1 binding to the miR-126 promoter in mouse endothelial cells treated with either DMSO or AZD6244. \pm SD $(n=3)$

integrity by reducing the expression of negative regulators of the VEGF pathway, such as SPRED-1 (Sprouty related protein 1) and the PI3K regulatory subunit 2 [52]. Several miR-126 targets have been identified that potentially account for the importance of miR-126 expression in endothelial cells. MiR-126 has also been shown to enhance endothelial cell proliferation by targeting the $3^{\prime}$ UTR of the Notch1 inhibitor delta-like 1 homolog (Dlk1) [53]. MiR-126 was also found to suppress the expression of the endothelial adhesion molecule vascular cell adhesion molecule 1 (VCAM1) and thereby plays a role in regulating vascular inflammation [54]. Other 
miR-126 targets that play a role in angiogenesis include VEGF [55], epidermal growth factor like domain 7

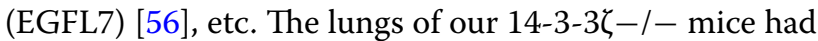
a significant miR-126 down-regulation, consistent with the defective lung development phenotype. Furthermore, reintroducing miR-126 to $14-3-3 \zeta$ knockdown endothelial cells rescued endothelial cell functions. Together, these data indicate that miR-126 down-regulation plays a critical role in the defective lung vasculature-mediated respiratory failure and neonatal lethality in $14-3-3 \zeta$ knockout mice, which may also have relevance for clinical syndromes of neonatal respiratory distress [57]. Notably, 14-3-3 $\zeta$ binds to many target proteins and regulates a wide variety of biological processes, thus miR-126 downregulation in 14-3-3 $-1-$ mice is likely one of the mechanisms underlying the developmental defects. A more comprehensive and in-depth future study will define other molecular mechanisms at play.

14-3-3s have been previously implicated to regulate angiogenesis in vitro and in lower organisms [58]. In our $14-3-3 \zeta-1-$ mouse model, loss of $14-3-3 \zeta$ in endothelial cells clearly inhibited angiogenesis during development in vivo and miR-126 downregulation contributes to this phenotype. Since 14-3-3 $\zeta$ plays an important role in activation of Raf/Mek/Erk pathway [36, 59], loss of 14-3$3 \zeta$ leads to inhibition of the Raf/Mek/Erk pathway. Erk downstream targets, Ets1 and Ets2 [60], are important regulators of miR-126 transcription [35]. Indeed, loss of 14-3-3 $\zeta$ in mouse endothelial cells resulted in reduced Erk activity, attenuated binding of Ets 2 to the miR-126 promoter, and ultimately repressed miR-126 expression (Fig. 5). Mice lacking both Ets1 and Ets2 have been reported to be embryonic lethal due to vascular defects and enhanced endothelial cell apoptosis [61], indicating an important role for Ets1 and Ets2, the miR-126 regulators, in maintenance of vascular integrity. Ets1 and Ets2 were found to regulate the expression of angiogenic genes such as matrix metalloprotease 9 (MMP9), Bcl-X(L) and c-IAP2 [61]. Our findings that loss of $14-3-3 \zeta$ led to reduced Ets 2 binding to the miR-126 promoter resulting in miR-126 downregulation and inhibited angiogenesis in 14-3-3 $\zeta-/-$ mouse model clearly established $14-3-3 \zeta$ as an upstream regulator of the Erk/Ets2/miR126/angiogenesis axis (Fig. 6).

Previously, we reported that $14-3-3 \zeta$ regulates transcription of miR-221 via the Erk target c-fos and the

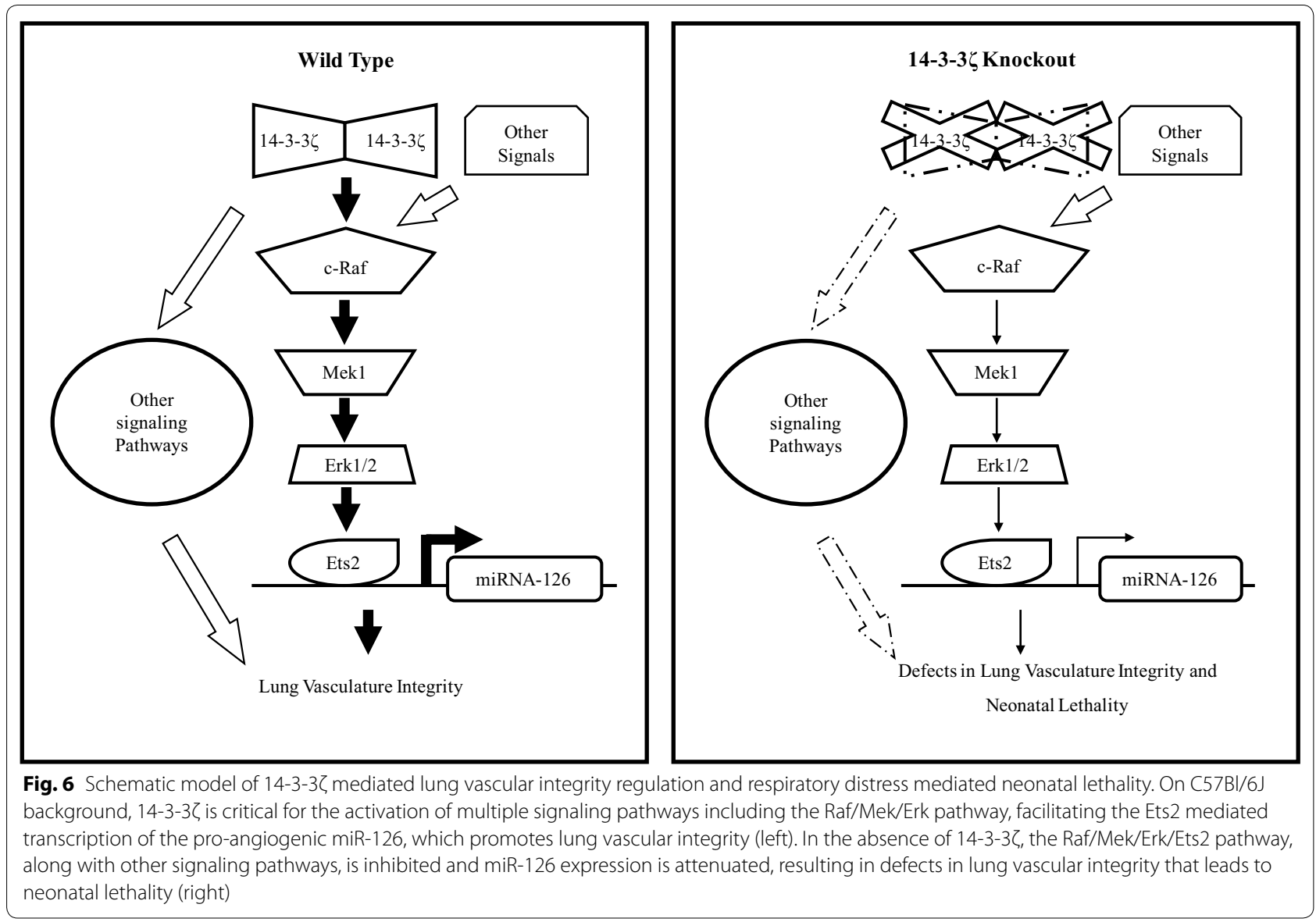


Jnk target c-Jun [62]. In this study, we found that 14-3$3 \zeta$ regulates miR-126 via the Erk/Ets2 pathway. These suggest an important role for 14-3-3 $\zeta$ in controlling miRNA transcription via its regulation of the Raf/Mek/ Erk pathway. Ets1 and Ets2 have been shown to regulate the transcription of multiple miRNAs such as miR-196b [63], miR-155 [64] which also play an important role in mediating endothelial cell function [65, 66]. Additionally Ets2 regulates the transcription of c-Myc [67] which can regulate miRNA processing via regulating drosha transcription [68]. Thus, it is plausible that $14-3-3 \zeta$ may regulate miRNA transcription and miRNA processing, ultimately miRNA expression and activity, which merits future in-depth studies. Additional tissue/organ defects due to $14-3-3 \zeta$ loss and other mechanisms may also contribute to the neonatal lethality observed on the $\mathrm{C} 57 \mathrm{Bl} / 6 \mathrm{~J}$ genetic background.

The lethality phenotype from $14-3-3 \zeta$ loss was most severe on a C57Bl/6J genetic background and could be rescued by outbreeding to $\mathrm{CD}-1$ and backcrossing to $\mathrm{FVB} / \mathrm{NJ}$, suggesting that the genetic background plays an important role in this phenotype. The molecular mechanisms of this dramatic phenotypic difference in different genetic backgrounds remains to be fully understood. Since 14-3-3 $\zeta$ can bind to many different target proteins to regulate various biological processes, it is possible that one or more such target proteins important for lung development are coded by gene(s) hypomorphic on the $\mathrm{C} 57 \mathrm{Bl} / 6 \mathrm{~J}$ genetic background. Interestingly, we have observed that miR-126 expression in the lungs of C57Bl/6J mice is significantly lower as compared to that in the $\mathrm{FVB} / \mathrm{NJ}$ and $\mathrm{CD}-1$ mice, suggesting that downregulation of miR-126 from 14-3-3 3 -loss may lead to more severe biological consequences on the $\mathrm{C} 57 \mathrm{Bl} / 6 \mathrm{~J}$ mice than in the $\mathrm{FVB} / \mathrm{NJ}$ and $\mathrm{CD}-1$ mice. Identifying the genes differentially expressed on the C57Bl/6J mouse strain that contributed to $14-3-3 \zeta$-mediated lethality may have important clinical implications. For example, the genes that contributed to $14-3-3 \zeta$-mediated lethality on the C57Bl/6J mouse strain may predict patients' therapeutic response versus adverse side effects when targeting the 14-3-3 $\zeta$ and downstream pathways which can guide the optimization of personalized therapy in the future.

\section{Conclusions}

14-3-3 $\zeta$ plays important functions in mouse lung development. Loss of 14-3-3 3 resulted in neonatal lethality in C57Bl/6 genetic background due to respiratory distress. 14-3-3 hypomorphic lungs had dysregulated angiogenesis mediated by inhibition of Erk-Ets2-miR-126 signaling pathway.

\section{Additional file}

Additional file 1: Figure S1. Characterization of the ES cell line RRR334. A RT-PCR to confirm that the cell line traps $14-3-3 \zeta$ schematic view of the integration of the gene trap vector in the 14-3-33 gene as described in the legend of Fig. 1. The arrowheads indicate the primers for PCR. Endogenous 14-3-3 is expressed both in wild-type ES cell control, TC1, and the mutant cell line RRR334. The exogenous mutant allele exists only in the RRR334 cell line. B Determination of the integration site of the gene trap vector using PCR. Arrowheads indicate the primers for PCR. The numbers on each lane of the gel indicate the primer position in the 14-3-3 "N"indicates negative control;" $M$ " indicates marker. The 1636 and 506-bp marker sizes are shown. C Western blot analysis of 14-3-3 expression level in 8 week old female B6/129 mice mammary gland. Quantification

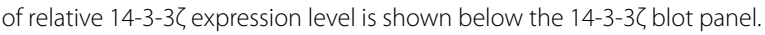
Figure S2. Characterization of truncated 14-3-3ろ. A Western blot of lysate of MCF7 vector control transfectants (Vc) and two MCF7 transfectants of HA-tagged $\mathrm{N}$-terminal fragment 139 amino acids of 14-3-3Z [C-terminal deletion ( $\triangle \mathrm{C} 1$ and $\triangle \mathrm{C} 12)$ ). Cells were treated with DMSO or $50 \mathrm{nM} \mathrm{MG132}$ for $4 \mathrm{~h}$. Endogenous 14-3-3 $\zeta$ was detected using 14-3-3 3 antibody, while the exogenous 14-3-3 C C-terminal deletion fragment was detected using HA antibody. B 14-3-3 N-terminal fragment did not affect p-Mek1 and p-Akt levels. Western blot on lysates from the indicated transfectants were performed with indicated antibodies. $\beta$-Actin was used as loading control. C $14-3-3 \zeta \mathrm{N}$-terminal fragment did not affect proliferation in MCF-7 cells. MTT assay was performed on the three indicated transfectants. OD was measured at $570 \mathrm{~nm}$ and normalized to $650 \mathrm{~nm}$. Figure S3. 14-3-3Z

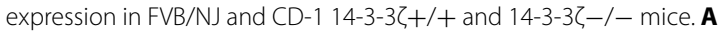
Analysis of $14-3-3 \zeta$ and $\beta$-actin in different organs in the CD-1 14-3-3 $++/+$ and $14-3-3 \zeta-1-$ mice by western blotting. Quantification of relative 14-3-3 expression level is shown below the western panel. B Analysis of $14-3-3 \zeta$ and $\beta$-actin in different organs in the FVB/NJ $14-3-3 \zeta+/+$ and

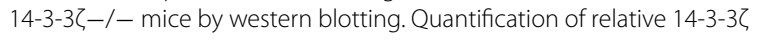
expression level is shown below the western panel. C Analysis of 14-3-3Z, $14-3-3 \beta, 14-3-3 \varepsilon$ and $\beta$-actin in the liver, kidney and lungs from FVB/NJ $14-3-3 \zeta+/+$ and $14-3-3 \zeta-/-$ mice by western blotting. Quantification of relative 14-3-3 $, 14-3-3 \beta, 14-3-3 \varepsilon$ expression level is shown below the western panel.

\section{Authors' contributions}

Conception and design: JY, SJ, QW, DY. Acquisition of data: JY, SJ, QW, PL, HW, YX, JW. Analysis and interpretation of data: JY, SJ, QW, YX, DY. Drafting or revising the article: JY, SJ, JP, RB, DY. Contributed essential reagents: JP. All authors read and approved the final manuscript.

\section{Author details}

1 Department of Molecular and Cellular Oncology, Unit 108, The University of Texas MD Anderson Cancer Center, 1515 Holcombe Boulevard, Houston, TX 77030, USA. ${ }^{2}$ Department of Genetics, The University of Texas MD Anderson Cancer Center, Houston, TX 77030, USA. ${ }^{3}$ University of Texas Health Science Center Graduate School of Biomedical Sciences, Cancer Biology Program, Houston, TX 77030, USA. ${ }^{4}$ Center for Molecular Medicine, China Medical University, Taichung 40402, Taiwan.

\section{Acknowledgements}

The authors thanks the following MDACC core facilities: Genetically engineered mouse facility for pro-nuclei injections, Laboratory Animal Genetic Services at Science Park for analysis of SSLP, the Histology Core Lab for tissue preparations, the shRNA and ORFome for shRNA constructs.

\section{Competing interests}

The authors declare that they have no competing interests.

\section{Availability of data and materials}

The data analyzed in this study were available at Mouse Genome Informatics site http://www.informatics.jax.org/. 


\section{Consent for publication}

Not applicable.

\section{Ethics approval and consent to participate}

All animal work was performed under an IACUC-approved protocol. University of Texas MD Anderson Cancer Center is an AAALAC accredited institution.

\section{Funding}

Grant support: This work was supported partially by National Institutes of Health Cancer Center Support Grant 5 P30-CA016672-39 (MDACC), DOD Postdoctoral Fellowship W81XWH-13-1-0022 (SJ), PO1-CA099031 project 4 (DY), RO1-CA112567-06 (DY), R01CA184836 (DY), R01CA208213 (DY), and China Medical University research fund (DY). D. Yu is the Hubert L. and Olive Stringer Distinguished Chair in Basic Science at MDACC.

\section{Publisher's Note}

Springer Nature remains neutral with regard to jurisdictional claims in published maps and institutional affiliations.

Received: 28 June 2017 Accepted: 23 October 2017 Published online: 02 November 2017

\section{References}

1. Darling DL, Yingling J, Wynshaw-Boris A. Role of 14-3-3 proteins in eukaryotic signaling and development. Curr Top Dev Biol. 2005;68:281-315.

2. Xu J, Acharya S, Sahin O, Zhang Q, Saito Y, Yao J, Wang H, Li P, Zhang L, Lowery FJ, et al. 14-3-3zeta turns TGF-beta's function from tumor suppressor to metastasis promoter in breast cancer by contextual changes of Smad partners from p53 to Gli2. Cancer Cell. 2015;27(2):177-92.

3. Jin J, Smith FD, Stark C, Wells CD, Fawcett JP, Kulkarni S, Metalnikov P, O'Donnell P, Taylor P, Taylor L, et al. Proteomic, functional, and domainbased analysis of in vivo 14-3-3 binding proteins involved in cytoskeleta regulation and cellular organization. Curr Biol CB. 2004;14(16):1436-50.

4. Angrand PO, Segura I, Volkel P, Ghidelli S, Terry R, Brajenovic M, Vintersten $K$, Klein R, Superti-Furga G, Drewes $G$, et al. Transgenic mouse proteomics identifies new 14-3-3-associated proteins involved in cytoskeletal rearrangements and cell signaling. Mol Cell Proteom MCP. 2006;5(12):2211-27.

5. Neal CL, Yu DH. 14-3-3 zeta as a prognostic marker and therapeutic target for cancer. Expert Opin Ther Targets. 2010;14(12):1343-54

6. Matta A, Siu KWM, Ralhan R. 14-3-3 zeta as novel molecular target for cancer therapy. Expert Opin Ther Targets. 2012;16(5):515-23.

7. Obsilova V, Kopecka M, Kosek D, Kacirova M, Kylarova S, Rezabkova L, Obsil T. Mechanisms of the 14-3-3 protein function: regulation of protein function through conformational modulation. Physiol Res. 2014:63:S155-64

8. Chang CC, Zhang C, Zhang Q, Sahin O, Wang H, Xu J, Xiao Y, Zhang J, Rehman SK, Li P, et al. Upregulation of lactate dehydrogenase a by 14-33zeta leads to increased glycolysis critical for breast cancer initiation and progression. Oncotarget. 2016;7:35270-83.

9. Lau JM, Wu C, Muslin AJ. Differential role of 14-3-3 family members in Xenopus development. Dev Dyn. 2006;235(7):1761-76.

10. Muslin AJ, Lau JM. Differential functions of 14-3-3 isoforms in vertebrate development. Curr Top Dev Biol. 2005;65:211-28

11. Hashiguchi M, Sobue $K$, Paudel HK. 14-3-3zeta is an effector of tau protein phosphorylation. J Biol Chem. 2000;275(33):25247-54.

12. Mateo I, Sanchez-Juan P, Rodriguez-Rodriguez E, Infante J, FernandezViadero C, Pena N, Berciano J, Combarros O. 14-3-3 zeta and tau genes interactively decrease Alzheimer's disease risk. Dement Geriatr Cogn Disord. 2008;25(4):317-20.

13. Lamba S, Ravichandran V, Major EO. Glial cell type-specific subcelIular localization of 14-3-3 zeta: an implication for JCV tropism. Glia. 2009;57(9):971-7

14. Omi K, Hachiya NS, Tanaka M, Tokunaga K, Kaneko K. 14-3-3zeta is indispensable for aggregate formation of polyglutamine-expanded huntingtin protein. Neurosci Lett. 2008:431(1):45-50.
15. Richard M, Biacabe AG, Streichenberger N, Ironside JW, Mohr M, Kopp N, Perret-Liaudet A. Immunohistochemical localization of 14.3.3 zeta protein in amyloid plaques in human spongiform encephalopathies. Acta Neuropathol. 2003;105(3):296-302.

16. Keshamouni VG, Michailidis G, Grasso CS, Anthwal S, Strahler JR, Walker A, Arenberg DA, Reddy RC, Akulapalli S, Thannickal VJ, et al. Differential protein expression profiling by iTRAQ-2DLC-MS/MS of lung cancer cells undergoing epithelial-mesenchymal transition reveals a migratory/invasive phenotype. J Proteome Res. 2006;5(5):1143-54.

17. Li ZG, Zhao J, Du YH, Park HR, Sun SY, Bernal-Mizrachi L, Aitken A, Khuri FR, Fu HA. Down-regulation of 14-3-3 zeta suppresses anchorage-independent growth of lung cancer cells through anoikis activation. Proc Natl Acad Sci USA. 2008;105(1):162-7.

18. Neal CL, Yao J, Yang WT, Zhou XY, Nguyen NT, Lu J, Danes CG, Guo H, Lan $\mathrm{KH}$, Ensor J, et al. 14-3-3 zeta overexpression defines high risk for breast cancer recurrence and promotes cancer cell survival. Can Res. 2009;69(8):3425-32.

19. Lu J, Guo H, Treekitkarnmongkol W, Li P, Zhang J, Shi B, Ling C, Zhou X, Chen T, Chiao PJ, et al. 14-3-3zeta Cooperates with ErbB2 to promote ductal carcinoma in situ progression to invasive breast cancer by inducing epithelial-mesenchymal transition. Cancer Cell. 2009;16(3):195-207.

20. Kobayashi R, Deavers M, Patenia R, Rice-Stitt T, Halbe J, Gallardo S, Freedman RS. 14-3-3 zeta protein secreted by tumor associated monocytes/ macrophages from ascites of epithelial ovarian cancer patients. Cancer Immunol Immunother. 2009;58(2):247-58.

21. Macha MA, Matta A, Chauhan SS, Siu KWM, Ralhan R. 14-3-3 zeta is a molecular target in guggulsterone induced apoptosis in Head and Neck cancer cells. BMC Cancer. 2010;10:655

22. Maxwell SA, Li ZG, Jaya D, Ballard S, Ferrell J, Fu HA. 14-3-3 zeta mediates resistance of diffuse large $B$ cell lymphoma to an anthracycline-based chemotherapeutic regimen. J Biol Chem. 2009;284(33):22379-89.

23. Lim GE, Albrecht T, Piske M, Sarai K, Lee JT, Ramshaw HS, Sinha S, Guthridge MA, Acker-Palmer A, Lopez AF, et al. 14-3-3zeta coordinates adipogenesis of visceral fat. Nat Commun. 2015;6:7671.

24. Cheah PS, Ramshaw HS, Thomas PQ, Toyo-Oka K, Xu X, Martin S, Coyle P, Guthridge MA, Stomski F, van den Buuse M, et al. Neurodevelopmental and neuropsychiatric behaviour defects arise from 14-3-3zeta deficiency. Mol Psychiatry. 2012;17(4):451-66.

25. Ramshaw H, Xu X, Jaehne EJ, McCarthy P, Greenberg Z, Saleh E, McClure B, Woodcock J, Kabbara S, Wiszniak S, et al. Locomotor hyperactivity in 14-3-3zeta $\mathrm{KO}$ mice is associated with dopamine transporter dysfunction. Transl Psychiatry. 2013:3:e327.

26. Xu X, Jaehne EJ, Greenberg Z, McCarthy P, Saleh E, Parish CL, Camera D, Heng J, Haas M, Baune BT, et al. 14-3-3zeta deficient mice in the BALB/C background display behavioural and anatomical defects associated with neurodevelopmental disorders. Sci Rep. 2015;5:12434.

27. Liu D, Bienkowska J, Petosa C, Collier RJ, Fu H, Liddington R. Crystal structure of the zeta isoform of the 14-3-3 protein. Nature 1995:376(6536):191-4.

28. Xiao B, Smerdon SJ, Jones DH, Dodson GG, Soneji Y, Aitken A, Gamblin SJ. Structure of a 14-3-3 protein and implications for coordination of multiple signalling pathways. Nature. 1995;376(6536):188-91.

29. Dougherty MK, Morrison DK. Unlocking the code of 14-3-3. J Cell Sci. 2004;117(Pt 10):1875-84.

30. Gluecksohn-Waelsch S. Lethal genes and analysis of differentiation. Science. 1963;142(3597):1269-76.

31. Turgeon B, Meloche S. Interpreting neonatal lethal phenotypes in mouse mutants: insights into gene function and human diseases. Physiol Rev. 2009;89(1):1-26.

32. Doetschman T. Influence of genetic background on genetically engineered mouse phenotypes. Methods Mol Biol. 2009;530:423-33.

33. Sanford LP, Kallapur S, Ormsby I, Doetschman T. Influence of genetic background on knockout mouse phenotypes. Methods Mol Biol. 2001;158:217-25

34. Wang S, Aurora AB, Johnson BA, Qi X, McAnally J, Hill JA, Richardson JA, Bassel-Duby R, Olson EN. The endothelial-specific microRNA miR-126 governs vascular integrity and angiogenesis. Dev Cell. 2008;15(2):261-71.

35. Harris TA, Yamakuchi M, Kondo M, Oettgen P, Lowenstein CJ. Ets-1 and Ets-2 regulate the expression of microRNA-126 in endothelial cells. Arterioscler Thromb Vasc Biol. 2010;30(10):1990-7. 
36. Fantl WJ, Muslin AJ, Kikuchi A, Martin JA, MacNicol AM, Gross RW, Williams LT. Activation of Raf-1 by 14-3-3 proteins. Nature. 1994;371 (6498):612-4.

37. Thorson JA, Yu LW, Hsu AL, Shih NY, Graves PR, Tanner JW, Allen PM, Piwnica-Worms H, Shaw AS. 14-3-3 proteins are required for maintenance of Raf-1 phosphorylation and kinase activity. Mol Cell Biol. 1998;18(9):5229-38

38. Hermeking H, Lengauer C, Polyak K, He TC, Zhang L, Thiagalingam S, Kinzler KW, Vogelstein B. 14-3-3 sigma is a p53-regulated inhibitor of G2/M progression. Mol Cell. 1997;1 (1):3-11.

39. Chan TA, Hermeking H, Lengauer C, Kinzler KW, Vogelstein B. 14-3-3 sigma is required to prevent mitotic catastrophe after DNA damage. Nature. 1999;401(6753):616-20.

40. Yang HY, Wen YY, Chen CH, Lozano G, Lee MH. 14-3-3 sigma positively regulates p53 and suppresses tumor growth. Mol Cell Biol. 2003;23(20):7096-107.

41. Ferguson AT, Evron E, Umbricht CB, Pandita TK, Chan TA, Hermeking H, Marks JR, Lambers AR, Futreal PA, Stampfer MR, et al. High frequency of hypermethylation at the 14-3-3 sigma locus leads to gene silencing in breast cancer. Proc Natl Acad Sci USA. 2000;97(11):6049-54.

42. I wata N, Yamamoto H, Sasaki S, Itoh F, Suzuki H, Kikuchi T, Kaneto H, Iku S, Ozeki I, Karino Y, et al. Frequent hypermethylation of CpG islands and loss of expression of the 14-3-3 sigma gene in human hepatocellular carcinoma. Oncogene. 2000;19(46):5298-302.

43. Suzuki H, Itoh F, Toyota M, Kikuchi T, Kakiuchi H, Imai K. Inactivation of the 14-3-3 sigma gene is associated with $5^{\prime} \mathrm{CpG}$ island hypermethylation in human cancers. Can Res. 2000;60(16):4353-7.

44. Li Q, Lu Q, Estepa G, Verma IM. Identification of 14-3-3sigma mutation causing cutaneous abnormality in repeated-epilation mutant mouse. Proc Natl Acad Sci USA. 2005;102(44):15977-82.

45. McGonigle S, Beall MJ, Feeney EL, Pearce EJ. Conserved role for 14-3-3epsilon downstream of type I TGFbeta receptors. FEBS Lett. 2001;490(1-2):65-9.

46. Kim H, Lee JH, Lee Y. Regulation of poly(A) polymerase by 14-3-3epsilon. The EMBO journal. 2003;22(19):5208-19.

47. Toyo-oka K, Shionoya A, Gambello MJ, Cardoso C, Leventer R, Ward HL, Ayala R, Tsai LH, Dobyns W, Ledbetter D, et al. 14-3-3 epsilon is important for neuronal migration by binding to NUDEL: a molecular explanation for Miller-Dieker syndrome. Nat Genet. 2003;34(3):274-85.

48. Steinacker P, Schwarz P, Reim K, Brechlin P, Jahn O, Kratzin H, Aitken A, Wiltfang J, Aguzzi A, Bahn E, et al. Unchanged survival rates of 14-3-3 gamma knockout mice after inoculation with pathological prion protein. Mol Cell Biol. 2005:25(4):1339-46.

49. Autieri MV, Haines DS, Romanic AM, Ohlstein EH. Expression of 14-3-3 gamma in injured arteries and growth factor- and cytokinestimulated human vascular smooth muscle cells. Cell Growth Differ. 1996;7(11):1453-60

50. Wang B, Ling S, Lin WC. 14-3-3Tau regulates Beclin 1 and is required for autophagy. PLoS ONE. 2010;5(4):e10409.

51. Lau JM, Jin X, Ren J, Avery J, DeBosch BJ, Treskov I, Lupu TS, Kovacs A, Weinheimer C, Muslin AJ. The 14-3-3tau phosphoserine-binding protein is required for cardiomyocyte survival. Mol Cell Biol. 2007;27(4):1455-66.

52. Fish JE, Santoro MM, Morton SU, Yu S, Yeh RF, Wythe JD, Ivey KN, Bruneau BG, Stainier DY, Srivastava D. miR-126 regulates angiogenic signaling and vascular integrity. Dev Cell. 2008;15(2):272-84.

53. Schober A, Nazari-Jahantigh M, Wei Y, Bidzhekov K, Gremse F, Grommes J, Megens RT, Heyll K, Noels H, Hristov M, et al. MicroRNA-126-5p promotes endothelial proliferation and limits atherosclerosis by suppressing DIk1. Nat Med. 2014;20(4):368-76.
54. Harris TA, Yamakuchi M, Ferlito M, Mendell JT, Lowenstein CJ. MicroRNA-126 regulates endothelial expression of vascular cell adhesion molecule 1. Proc Natl Acad Sci USA. 2008;105(5):1516-21.

55. Chen H, Li L, Wang S, Lei Y, Ge Q, Lv N, Zhou X, Chen C. Reduced miR-126 expression facilitates angiogenesis of gastric cancer through its regulation on VEGF-A. Oncotarget. 2014;5(23):11873-85.

56. Sun Y, Bai Y, Zhang F, Wang Y, Guo Y, Guo L. miR-126 inhibits non-small cel lung cancer cells proliferation by targeting EGFL7. Biochem Biophys Res Commun. 2010;391(3):1483-9.

57. Edwards MO, Kotecha SJ, Kotecha S. Respiratory distress of the term newborn infant. Paediatr Respir Rev. 2013;14(1):29-36 (quiz 36-27)

58. Bierings R, Beato M, Edel MJ. An endothelial cell genetic screen identifies the GTPase Rem2 as a suppressor of p19ARF expression that promotes endothelial cell proliferation and angiogenesis. J Biol Chem. 2008;283(7):4408-16

59. Freed E, McCormick F, Ruggieri R. Proteins of the 14-3-3 family associate with Raf and contribute to its activation. Cold Spring Harb Symp Quant Biol. 1994:59:187-93.

60. Chang F, Steelman LS, Lee JT, Shelton JG, Navolanic PM, Blalock WL, Franklin RA, McCubrey JA. Signal transduction mediated by the Ras/Raf/MEK ERK pathway from cytokine receptors to transcription factors: potential targeting for therapeutic intervention. Leukemia. 2003;17(7):1263-93.

61. Wei G, Srinivasan R, Cantemir-Stone CZ, Sharma SM, Santhanam R, Weinstein M, Muthusamy N, Man AK, Oshima RG, Leone G, et al. Ets1 and Ets2 are required for endothelial cell survival during embryonic angiogenesis. Blood. 2009;114(5):1123-30.

62. Rehman SK, Li SH, Wyszomierski SL, Wang Q, Li P, Sahin O, Xiao Y, Zhang $S$, Xiong $Y$, Yang J, et al. 14-3-3zeta orchestrates mammary tumor onset and progression via miR-221-mediated cell proliferation. Can Res. 2014;74(1):363-73.

63. Liao YL, Hu LY, Tsai KW, Wu CW, Chan WC, Li SC, Lai CH, Ho MR, Fang WL, Huang KH, et al. Transcriptional regulation of miR-196b by ETS2 in gastric cancer cells. Carcinogenesis. 2012:33(4):760-9.

64. Quinn SR, Mangan NE, Caffrey BE, Gantier MP, Williams BR, Hertzog PJ, McCoy CE, O'Neill LA. The role of Ets2 transcription factor in the induction of MicroRNA-155 (miR-155) by lipopolysaccharide and its targeting by interleukin-10. J Biol Chem. 2014;289(7):4316-25.

65. Sun HX, Zeng DY, Li RT, Pang RP, Yang H, Hu YL, Zhang Q, Jiang Y, Huang $L Y$, Tang $Y B$, et al. Essential role of microRNA-155 in regulating endothelium-dependent vasorelaxation by targeting endothelial nitric oxide synthase. Hypertension. 2012;60(6):1407-14.

66. Plummer PN, Freeman R, Taft RJ, Vider J, Sax M, Umer BA, Gao D, Johns C, Mattick JS, Wilton SD, et al. MicroRNAs regulate tumor angiogenesis modulated by endothelial progenitor cells. Can Res. 2013;73(1):341-52.

67. Al-azawi D, Ilroy MM, Kelly G, Redmond AM, Bane FT, Cocchiglia S, Hill AD, Young LS. Ets-2 and p160 proteins collaborate to regulate c-Myc in endocrine resistant breast cancer. Oncogene. 2008;27(21):3021-31.

68. Wang X, Zhao X, Gao P, Wu M. c-Myc modulates microRNA processing via the transcriptional regulation of Drosha. Sci Rep. 1942;2013:3.

\section{Submit your next manuscript to BioMed Central and we will help you at every step:}

- We accept pre-submission inquiries

- Our selector tool helps you to find the most relevant journal

- We provide round the clock customer support

- Convenient online submission

- Thorough peer review

- Inclusion in PubMed and all major indexing services

- Maximum visibility for your research

Submit your manuscript at www.biomedcentral.com/submit 